\title{
Modeling and Analysis of a Ship's Diesel Engine Thermal System
}

\author{
Chen Zuotian*, Lu Jia, Dong Qingfeng, Hu cun \\ China Satellite Maritime Tracking and Control Department, Jiang Yin 214431, China
}

\begin{abstract}
This article takes the diesel thermal system as the research object, which simplifies the diesel engine system into four subsystems. This article conducts a thermodynamic analysis of the specific equipment of the host thermal system. Simulink tools in MATLAB are used to build simulation models of specific equipment in the thermal system, and a modular model is used to build a subsystem model based on the specific equipment model. Then, the thermal coupling relationship between the subsystems is used to form the thermal system. The overall model obtains the temperature values of the key nodes of the thermal system network, so that it can predict the temperature changes of the thermal pipeline system nodes of the diesel engine under various operating conditions.
\end{abstract}

\section{Introduction}

With the introduction of thermal management ${ }^{[1-2]}$, the requirements for cabin heat distribution are more accurate. It is of great research significance to build a model of the ship'sdiesel thermal system and simulate the thermal characteristics of thediesel thermal system. This article simplifies the mainframe thermal system into four subsystems, multiple heat exchange instruments [3-4], connecting pipeline networks and other auxiliary equipment. These systems can complete energy conversion ${ }^{[5-6]}$ and heat transfer. There are links between heat transfer and mechanical parts. By analyzing the energy consumption of the thermal system, we establish a mathematical model of the thermal system ${ }^{[7-8]}$, and study the parameter characteristics of the thermal system through computer simulation. By analyzing the working process of the subsystems of the thermal system and its main equipment, we establish a mathematical model of the thermal system by simplifying and assuming each link. we write a system simulation program through Simulink based on the mathematical model. The system performs static and dynamic simulations. In the simulation process, the system is debugged and analyzed by inputting the boundary conditions and the original parameters, from module debugging to subsystem debugging in order, and finally debugging the entire system.

\section{Thermal system network composition}

The thermal system consists of the diesel intake and exhaust system, cooling water system, oil system and fuel system. The cooling water system is divided into high temperature fresh water system, low temperature fresh water system and sea water system. Although the thermal system of the diesel is divided into four systems, they are not independent. There is a coupling relationship between them. The four systems cross each other. The cooling water system is the core of heat exchange. The following points are related to other systems:(1) Coupling of cooling water system and airframe, which takes away the heat of mainframe body through cooling cylinder liner;(2) The coupling of the cooling water system and the intake - exhaust systems, which cools the pressurized air through the air cooler and carrys heat;(3) The coupling of the cooling water system and the lubrication system, the oil is cooled by the oil cooler, and the heat is also transferred to the cooling water;(4) The coupling of the cooling water system and the fuel system, cooling the fuel by the seawater of the fuel cooler of the cooling system, cooling the fuel and taking away the corresponding heat. The cooling water system is relatively complicated. There is a coupling relationship between the internal high \& low temperature fresh water system and the seawater system.

\section{3 mathematical model}

\subsection{Engine heat transfer model}

The heat load of the diesel cylinder liner is taken away by cooling water, which is calculated by numerical simulation calculation of the combustion and heat release of the cylinder. However, the calculation process is quite complicated and requires a lot of test parameters. This article estimates it based on experience. The revised empirical formula is:

$$
Q_{g}=0.0637 z D^{1.73} S^{0.575} n^{0.71} \lambda\left\{1+1.5 \frac{S}{D}\right\}
$$

Among them:

Z-number of cylinders d-cylinder bore $\mathrm{S}$-piston stroke n-Engine speed 
$\lambda$-correction factor

\section{2 heat exchanger model}

The heat transfer of the fluid through the heat exchanger can be solved by the following formula

$$
Q_{H R}=c M\left(t_{\text {out }}-t_{\text {in }}\right)
$$

Where is the heat exchange (W) of the heat exchanger; $Q_{H R} \mathrm{C}$ specific heat capacity of the fluid flowing through the heat exchanger $\left(\mathrm{J} / \mathrm{kg} \cdot{ }^{\circ} \mathrm{C}\right) ; t_{\text {out }}$ Is the fluid temperature $\left({ }^{\circ} \mathrm{C}\right)$ flowing out of the heat exchanger; $t_{i n}$ Is the fluid temperature $\left({ }^{\circ} \mathrm{C}\right)$ flowing into the heat exchanger; Mass flow rate $(\mathrm{kg} / \mathrm{s})$ of the fluid flowing through the heat exchanger.

In this article, the Wärtsilä main engine of type $8 \mathrm{~L} 460 \mathrm{C}$ is selected. The main engine has a rated power of $8400 \mathrm{KW}$ and uses light diesel oil. The maximum seawater temperature in the sea area is set to $32^{\circ} \mathrm{C}$ and the temperature of the low temperature fresh water inlet is $36^{\circ} \mathrm{C}$.

\section{4 simulation results and analysis}

The mathematical model of each part of the system is established by theoretical analysis or experimental data and characteristic curve fitting. In addition, for the above-mentioned integrated thermal management system, the following considerations were made in the steady-state simulation modeling of the integrated thermal management system:(1) The mathematical model of the system equipment involved in this article is to simulate the operation of the entire system, so the mathematical model established can mainly reflect the relationship between input and output parameters.(2) Drawing on the idea of modular modeling, we divide the system into many blocks and establish mathematical model respectively. The system simulation is carried out on the MATLAB simulation platform to form a visual, portable, and reusable graphical simulation module based on the MATLAB simulation platform. The whole system is divided into four subsystems, the mathematical models of each subsystem are established, and then each subsystem is connected into the entire system. According to the establisheddiesel thermal system simulation model, we perform a steady-state analysis on the system. Input the initial boundary conditions of the system into the system model, we wait until the output results are in a stable state. The load for the diesel thermal system is $100 \%, 90 \%, 75 \%$ steady state calculation.

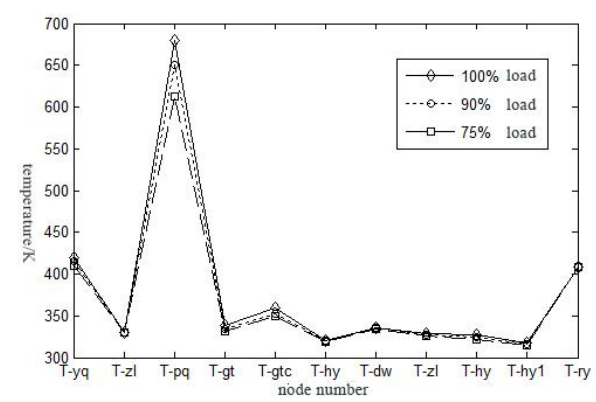

Fig 1. Node temperature changing with the load of the diesel

Figure 1 is the change of the temperature of each node in thediesel thermal system with different values of the diesel load. When the load condition of the diesel is reduced, the temperature at the fluid node outlet of each heat exchanger is reduced, but the degree of decrease is not large. The inlet and outlet temperature of the cooling water in the cylinder liner are significantly reduced. The amplitude is the most obvious, because the reduction of the power of the host will directly affect the exhaust temperature. The temperature between other nodes in the system will be reduced to varying degrees. The characteristic parameters of each key node obtained from the steady-state simulation provide great guidance for ship operation management. Through the steady state analysis, the temperature values of each node of thediesel can be obtained, which can determine whether the ship is in a safe and stable state and provide theoretical basis and decision-making direction for the safe, efficient and sustainable operation of the ship. Through the analysis of the node temperature in different working conditions, the energy saving potential of thediesel components can be found out, and the thermal energy emitted by thediesel combustion and heat release can be fully and reasonably used to improve the energy utilization level.

\section{5 dynamic simulation}

The ship frequently operates in complex and constantly changing environments. In this situation, it is particularly significant to study the diesel of the ship under variable operating conditions. The operating parameters of the diesel under extreme conditions can be derived to predict whether the equipment of the diesel can operate normally under extreme conditions. The following figure shows the change of the exhaust temperature of thediesel when the load of the diesel of the ship changes from $100 \%$ to $80 \%$.

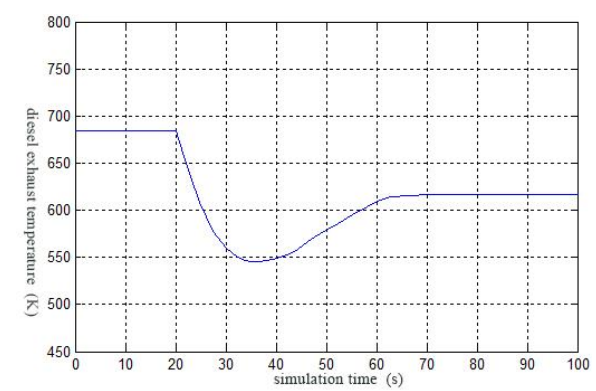

Fig 2. The exhaust gas temperature change curve of the diesel 
In Figure 2, it can be seen that under 100\% load conditions, the smoke emission temperature of the host is stable at $680 \mathrm{~K}$, which decreases from $100 \%$ to $80 \%$ when the load suddenly changes at 20 s. When the power of the diesel changes, the speed of the diesel will change, so when the exhaust temperature of thediesel drops to the lowest value, it will slowly increase back to the new steady state value, so as to reach $80 \%$ of the new operating temperature. The change in the speed of thediesel directly affects the fuel injection quantity of thediesel, so when the power of thediesel changes, the fuel injection quantity will also change accordingly.

\section{6 the conclusion}

The following conclusions can be drawn from the above modeling calculations and analysis:(1) Because the energy for the heat exchange of each system comes from the heat released by the combustion of the engine, when the load of thediesel is reduced, the temperature of the nodes passing through each heat exchanger is reduced to a certain extent, so the heat exchange capacity of these nodes will reduce.(2) Through the simulation of the thermal system of thediesel, the temperature of each node of the fluid network system can be simulated under various operating conditions of thediesel. The simulation model can indicate the direction of fault diagnosis during ship operation and provide ideas and directions for energy saving management of ship operations. Aiming at the comprehensive utilization of the energy of the thermal system of the ship's diesel, this paper establishes a mathematical model of the fluid network of the diesel's thermal system and calculates the temperature of the key nodes of the thermal system's network. The temperature parameters of these nodes are consistent with the actual trend.

\section{Corresponding author}

Chen Zuotian (1991-), male, master, engineer. engaging in diesel thermal energy research. Phone:15261629223, Email: zuotian_925@163.com

\section{References}

1. QIAN Zuo-qing, JIA Xiao-jun. Optimization design and thermal performance of roll-on-roll-off ship cooling water system[J]. Shipbuilding of China, 2005, 46(02): 43-50

2. FU xiao, ZENG fan-ming. Research on the Bayesian state reasoning methods for marine diesel cooling system[J]. Ship Science and Technology, 2014,08: 42-46

3. LAN Feng, LU Ya-guo, LU Bing. Research on Simulation of lubrication system for marine transmission[J]. Ship Engineering, 2011, 33 (05): $39-42$.

4. HU Peng-yu. Thermodynamic analysis and optimization of small marine steam power
system[D]. Harbin: Harbin Engineering University, 2012

5. Zafer Utlu, Harun Kemal Ozturk, Olcay Ersel Canyurt, Arif Hepbasli. An Application of Genetic Algorithm Search Techniques to the Future. Total Exergy Input/Output Estimation [J]. Energy Sources.2009, 30(21): 119-135

6. Ameri, Mohammad. The study of the effects of gas turbine inlet air cooling on the heat recovery boiler performance. Proceedings of the 7th Biennial Conference on Engineering Systems Design and Analysis, ESDA 2004 (1): 915-920

7. Talom L.Hugues. Heat Recovery from Automotive Engine[J]. Applied Thermal Engineering, 2009, (29): 439-444

8. XU Zhi-ying, ZHUANG Da-ming. Research on thermal management of aircraft fuel system[J]. Journal of Aerospace Power, 2007, 22(11): 1833-1837 